Cronfa - Swansea University Open Access Repository

This is an author produced version of a paper published in :

Transportation Planning and Technology

Cronfa URL for this paper:

http://cronfa.swan.ac.uk/Record/cronfa30619

\title{
Paper:
}

Musselwhite, C. (in press). Assessment of computer-based training packages to improve the safety of older people's driver behaviour. Transportation Planning and Technology, 1-16.

http://dx.doi.org/10.1080/03081060.2016.1238571

This article is brought to you by Swansea University. Any person downloading material is agreeing to abide by the terms of the repository licence. Authors are personally responsible for adhering to publisher restrictions or conditions. When uploading content they are required to comply with their publisher agreement and the SHERPA RoMEO database to judge whether or not it is copyright safe to add this version of the paper to this repository. http://www.swansea.ac.uk/iss/researchsupport/cronfa-support/ 
Musselwhite, C.B.A. (in press) Assessment of computer-based training packages to improve the safety of older people's driver behaviour. Transport Planning \& Technology. To be published 2017 vol 40 edition 1.

\section{Assessment of computer-based training packages to improve the safety of older people's driver behaviour}

\section{Charles B A Musselwhite}

Associate Professor/Reader in Gerontology,

College of Human and Health Sciences,

Swansea University,

Singleton Park,

Swansea, SA2 8PP.

\section{Email: c.b.a.musselwhite@swansea.ac.uk}

Tel: 01792518696

\section{Abstract}

Examination of police records in Wales (STATS19 database) suggests older drivers are over represented in collisions turning across traffic and those involving failure to look properly, failure to judge the other vehicle or person's path and performing a poor manoeuvre. A convened expert group suggests this is due to changes in attention, cognitive overload, processing speed, perceptual speed, working memory, task switching and eyesight associated with ageing. Training using computer-based packages can improve these cognitive and physiological issues associated with age. Performance on Useful Field of View (UFoV), Delayed Recall, Maze test and Dual $\mathrm{N}$ task computer tasks have all been shown to be related to number of crashes older drivers have. Of these only UFOV and Dual $\mathrm{N}$ task training improvements have been demonstrated to translate into improved driver behaviour, but overall more research is needed.

Keywords: Older drivers, cognitive training, driver behaviour, road traffic collisions, road user safety

\section{Word count: -}


Musselwhite, C.B.A. (in press) Assessment of computer-based training packages to improve the safety of older people's driver behaviour. Transport Planning \& Technology. To be published $2017 \mathrm{vol}$ 40 edition 1.

\section{Introduction}

Society across the globe is rapidly ageing due to a combination of falling fertility rates and substantial increases in life expectancy (UN, 2013). In 1950, there were 384,704,000 people aged over 60 years of age across the world, representing only 8.6 per cent of the global population, now there are $840,628,000$ people over 60 , representing 11.7 per cent of the population (UN, 2013). Projections suggest there will be $2,020,359,000$ people aged over 60 , representing 21.2 per cent of the global population by 2050 (UN, 2013). This pattern of ageing is happening across the world, but the rate of increase is faster in wealthier countries. For example, the United Kingdom (UK) will reach $25 \%$ of the population being over 60 by around 2030 (ONS, 2013).

In the UK, as in many western societies, older people are fitter and more active than previous generations. Ageing does not change the engagement people have with a hypermobile society, desiring to travel large distances, more frequently than previous generations. They may still be working, have caring responsibilities (for other older people, for children or grandchildren, for example) and social and recreational networks that span over wide geographical distances. However, those aged over 70 are the group most likely to cite difficulties in accessing shops, banks and hospitals and problems in staying connecting with local communities, especially when no longer driving and state transport as being a barrier to engaging in social activities (see Ormerod et al., 2015 and Musselwhite, 2011 for an overview). Recent figures from Great Britain suggest around 342,000 over 75 year olds 'feel trapped' in their own homes through lack of suitable transport (WRVS, 2013).

Older people are more likely to give-up driving due to health, finance or confidence issues; yet giving up driving has repeatedly been shown to related to a decrease in wellbeing and an increase in depression and related health problems, including feelings of stress and isolation and also increased mortality (Edwards et al., 2009b;Fonda et al., 2001; Ling and Mannion, 1995; Marottoli, 2000; Marottoli et al., 1997; Musselwhite and Haddad, 2010a; Musselwhite and Shergold, 2013; Peel et al., 2001; Ragland et al., 2005 Windsor et al. 2007; Zieglar and Schwannen. 2013). Hence, it is of increasing importance to examine how to keep older people mobile, especially in terms of driving.

In the UK, similar to other western societies, casualty rates for older drivers per miles driven is at its lowest at 70 years of age and begins to increase from around 75 years. Most of this increase is almost certainly due to frailty as suggested by the number of Killed and Seriously Injured (KSI) rising faster than all casualties (DfT, 2015). That said, older drivers from the age of 70 become more likely to be "at blame" for collisions they are involved in, according to official police records (Clarke et al., 2009; Mitchell, 2013). Clarke et al. (2009) reviewed STATS19 data (police on-scene incident record in Great Britain) and found older drivers are over represented, compared to younger age groups, as an at fault casualty in collisions at junctions, in merging traffic, with turns across the road and in busy traffic. Van Elsland and Dominque (2000) estimated that 19\% of older driver collisions are due to their cognitive abilities being overwhelmed and that if eyesight issues are added the figure rises to $40 \%$ (Staplin et al., 2003a,b). Langford et al. (2006) suggest that low mileage drivers entirely make-up the increase in numbers in this category post 75 years of age, suggesting this maybe as a result of selfselection where poorer drivers reduce the amount they drive, but it could also be due to types of road 
Musselwhite, C.B.A. (in press) Assessment of computer-based training packages to improve the safety of older people's driver behaviour. Transport Planning \& Technology. To be published $2017 \mathrm{vol}$ 40 edition 1.

high milers might be driving on, motorways, for example, being safer roads per mile driven than local roads (see Musselwhite, 2011 for a review).

This research undertaken for this paper sought to investigate how far training can be undertaken that might help overcome some of the cognitive changes associated with ageing in later life. Specifically computer-based training packages were examined, with a view that they are easy and flexible to administer, being able to be completed at home or with a trained driving instructor at a driver training centre.

\section{Methodology}

\subsection{Design}

A desk based research project was supplemented by the meeting of an expert advisory group of people with expertise in driving in later life, comprising of 14 individuals: 5 gerontology academics, 2 geriatric-medicine academics, 2 geriatric-medicine practitioners and 5 older-age specialist qualified driver instructors. These were recruited from a database of interested parties held by the Older People's Research and Development Network Wales (OPAN Cymru), where an advert was placed asking for experts to come forwards. A total of 10 people responded and a further four were snowballed from the original participants to include driving instructors $(n=2)$ and geriatric medicine practitioners $(n=2)$. An extension to the expert advisory group also included a panel of five cognitive psychologists working at across four universities in Wales. The project examined how far computer based training packages could improve older people's driving behaviour. This involved three stages (1) trawling STATS19 databases and examination of previous literature to identify contributory factors associated with older people's collisions; (2) identifying age related physiological and cognitive changes that might explain the contributory factors in the collisions and; (3) identifying computer based programmes which have been purported to be related to driver behaviour and therefore could form the basis of a training package to improve older people's driver behaviour.

\subsubsection{Stage one: trawling STATS19 databases and other literature}

STATS19 is a standardised database of information collected by police in attendance at a Road Traffic Collision (RTC) where there has been a casualty. It is completed by trained police at the scene of every injury-related RTC across Great Britain. Data collected includes location, vehicles involved, gender, and, crucially for this project, age, manoeuvres undertaken at the time of the collision and contributory factors leading to the collision. Contributory factor data is determined by the police at the time of the collision and the police can select up to six of 77 categories (and a further category for "other contributory factor") for each casualty involved. The police must select whether the factor they have chosen is either a "very likely" or a "possible" factor in the collision. The validity and reliability of the dataset is, however, questionable. The dataset only links to $33 \%$ of hospital records collected on RTCs (DfT, 2012) and the contributory factors are recorded at the discretion of the police in attendance and no research exists to assess validity and consistency of such data. The STATS19 dataset was examined for Wales between the years of 2003 and 2012 inclusive. A Welsh dataset was 
Musselwhite, C.B.A. (in press) Assessment of computer-based training packages to improve the safety of older people's driver behaviour. Transport Planning \& Technology. To be published $2017 \mathrm{vol}$ 40 edition 1.

used for convenience with the knowledge that it covers a variety of different contexts, urban, suburban, and rural areas, and that the population is not significantly different from that across the whole of the United Kingdom. The dataset was examined in Excel and converted into SPSS for analysis. Differences between the main contributory factors and any manoeuvres undertaken where the driver was aged over 70 years, compared with drivers under the age of 70 were tabulated and examined. This was supplemented by a literature review by the author. Seventy years of age was chosen as a cut off period as casualty rates are at their lowest at 70 years and then begin to increase in those just older (DfT, 2015; Mitchell, 2013).

2.1.2 Stage two: Identifying age related physiological and cognitive changes that might explain the contributory factors involved in the collision.

The findings from stage one were presented to the expert advisory group. These people met in person in an hour long focus group and were presented the findings from stage one. They discussed the findings and concluded the key physiological and cognitive changes associated with ageing that could be responsible for the contributory factors identified in stage one. The findings were also presented via email to the group of cognitive psychologists with instructions to conclude key physiological and cognitive changes that could be responsible for the contributory factors identified in stage one. This took a two email process, one with their open comments and two to verify and validate any differences between individuals to come up with a definitive list, as would have happened had they met in person as part of a discussion group.

2.1.3 Stage three: Identifying computer based programmes which may help older drivers improve road user safety.

The expert group, in the second half of the focus group, were then tasked to identify a list of computer programmes or tasks purported to be related to driver behaviour that older people could complete that matched three criteria: (i) that performance on the computer programme is related to driver performance; (ii) training can improve performance on the computer task and; (iii) improvement in performance on the computer task is synonymous with an improvement in driver performance. Recommendations for future computer based tests are then discussed. This was supplemented by the author with a literature review. The cognitive psychologists also performed this task remotely via email, following the same pattern as the focus group of experts. Once again a second email highlighted discrepancies or similarities to be discussed and decided upon, so a definitive list could be produced, matching the process of the focus group.

\subsection{Analysis}

STATS19 data was entered into Excel and collisions (vehicles involved, manoeuvres and contributory factors) and casualty (age, gender, injury type - classified as fatal, serious or slight injury) datasets matched. Data for Wales between 2003 and 2012 inclusive were extracted, covering a 10 year period. Data was further coded into two categories, those aged over 70 and those aged under the age of 70 for comparison. As before, seventy years of age was chosen as a cut off period as casualty rates are known to increase from after 70 years of age (Mitchell, 2013). Where no age was given then data was 
Musselwhite, C.B.A. (in press) Assessment of computer-based training packages to improve the safety of older people's driver behaviour. Transport Planning \& Technology. To be published $2017 \mathrm{vol}$ 40 edition 1.

omitted. Data was placed into SPSS for further analysis to find significant differences using t-tests on causes of collision for those aged 70 years or over and those aged under 70 years of age. Significant differences are reported in stage one of the findings.

In terms of the expert advisory focus group, key findings for the project were extracted and agreed upon with the participants at the focus group using sticky-notes and charts which were photographed for recording purposes until general consensus was achieved. In terms of the group of cognitive psychologists, correspondence was via email. Replies in stage two and three were assembled together and re-presented to the cognitive psychologists for validation and to come to a general consensus to match that happening in the focus groups.

\section{Findings}

\subsection{Stage one: trawling STATS19 datasets and other literature.}

Usable STATS19 data identified 141,378 drivers involved in road traffic collisions where there were reported casualties in Wales between 2003 and the end of 2012, of these 6,965 were where the driver was 70 years or over and 134,378 were where the driver was 69 or under. Compared to other age groups older people over the age of 70 are more involved in collisions that involve failures of attention and judgement, $48 \%$ failed to look properly, compared to $40 \%$ across all age groups, a subsequent ttest suggested this was significant $(t=2.93 ; p<0.01), 27 \%$ failed to judge the other vehicle or person's path, compared to $20 \%$ across all age groups, a significant difference $(t=2.77 ; p<0.01)$ and $16 \%$ performed a poor manoeuvre compared to $13 \%$ of all ages $(t=2.07 ; p<0.05)$. Older drivers are also over represented in collisions that involve turning right (across traffic), $13 \%$ of collisions for over 70 s, compared to $7 \%$ for under 70 year olds, again a significant difference $(t=2.45 ; p<0.01)$.

A review of the literature suggests older people are over represented in collisions at junctions, in merging traffic, with turns across the road and in busy traffic (Clarke et al., 2009) esp. judgements of relative speed, time gap judgements (Oxley et al., 2006; Preusser et al., 1998), which broadly correlates with the STATS19 data of turning across traffic and failure to look properly and judge other people's speed. They are also more likely to have difficulties in navigating unfamiliar routes (Holland, 2001), something not investigated on a STATS19 form. Research also suggests older people have difficulty maintaining speed and tracking (Brendemuhl, Schmidt and Schenk, 1988; Mussewhite and Haddad, 2008, 2010b; Schlag, 2003). They may also have attentional difficulties in being distracted by radio, passengers, outside (Holland, 2001; Musselwhite and Haddad, 2008, 2010) and perceptual difficulties in inability to see very well under poor lighting (glare, darkness, luminance) (Janke, 1994; Musselwhite and Haddad, 2008, 2010b). There is also literature highlighting that older people have poorer reaction times when driving (Musselwhite and Haddad, 2008, 2010b).

\subsection{Stage two: Identifying age related physiological and cognitive changes that might explain the contributory factors involved in the collision.}

The findings from stage one were presented to the expert advisory group and were then mapped to specific physiological and cognitive difficulties faced by older people (table 1). The expert advisory 
Musselwhite, C.B.A. (in press) Assessment of computer-based training packages to improve the safety of older people's driver behaviour. Transport Planning \& Technology. To be published $2017 \mathrm{vol}$ 40 edition 1.

group identified six cognitive issues and one cognitive/physiological issue that could be related to the types of error made in older people's collisions:

(1) Attention. The literature suggests that older age is synonymous with deficits in selective and sustained attention (Zanto and Gazzaley, 2014).

(2) Cognitive Overload. Older people reach maximum task difficulty of increased processing of multiple-tasks quicker than younger people. That is they are unable to process as much information simultaneously than younger people (Zanto and Gazzaley, 2014). Switching between tasks can also pose more problems for older people than it can for those younger (Zanto and Gazzaley, 2014). This may be due to the brain already using compensatory pathways where direct routes have diminished over time

(3) Cognitive processing speed. How quickly a person can process changes in the environment tends to deteriorate over time. This is often measured in terms of reaction time, for example, it is well documented that reaction time shortens from infancy to around 20 years of age, then increases slowly to around 70 years of age and beyond (Der and Deary, 2006; Jevas and Yan, 2001; Welford, 1977). A person over the age of 65 can have reactions times up to 22 times slower than that of someone of 30 years of age, though it is noted many factors contribute to this, not just cognition (for example not being able to shift feet quickly between correct pedals or alter course through moving steering wheel promptly) (see Holland, 2001).

\begin{tabular}{|c|c|c|c|c|c|c|c|}
\hline 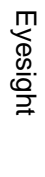 & 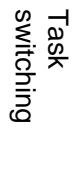 & 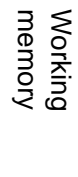 & 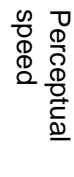 & 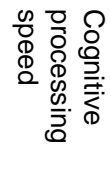 & 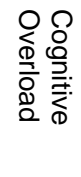 & 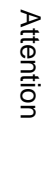 & 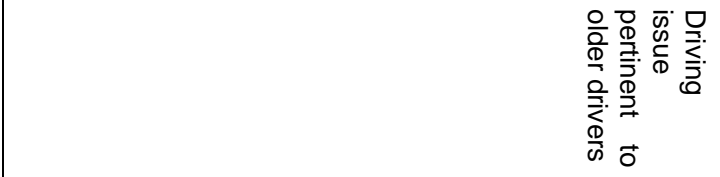 \\
\hline$\times$ & $\times$ & $\times$ & $\times$ & $\times$ & $\times$ & $\times$ & 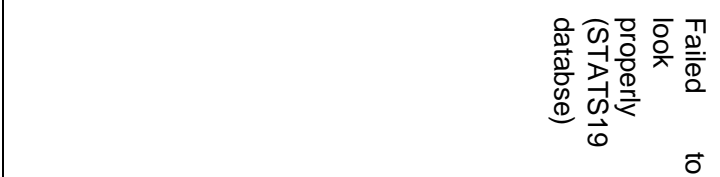 \\
\hline$\times$ & $x$ & & $\times$ & & & $\times$ & 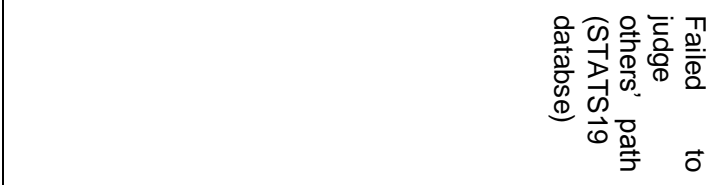 \\
\hline$\times$ & $x$ & $x$ & & & & $x$ & 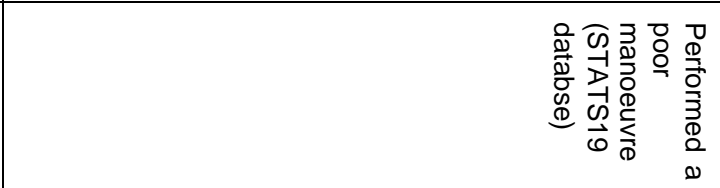 \\
\hline$\times$ & $x$ & $x$ & $x$ & $x$ & $x$ & $\times$ & 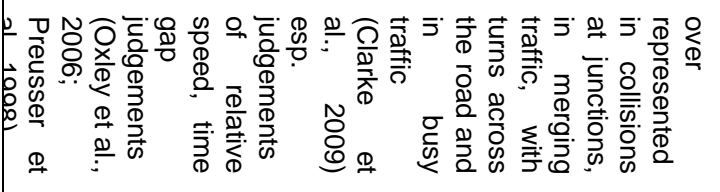 \\
\hline$\times$ & $\times$ & $\times$ & & $\times$ & $x$ & $\times$ & 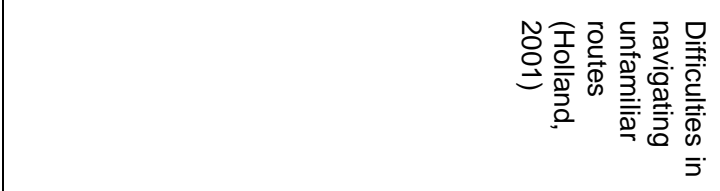 \\
\hline
\end{tabular}


Musselwhite, C.B.A. (in press) Assessment of computer-based training packages to improve the safety of older people's driver behaviour. Transport Planning \& Technology. To be published $2017 \mathrm{vol}$ 40 edition 1.

\begin{tabular}{|c|c|c|c|c|c|c|c|}
\hline$\times$ & & & $\times$ & & & $\times$ & 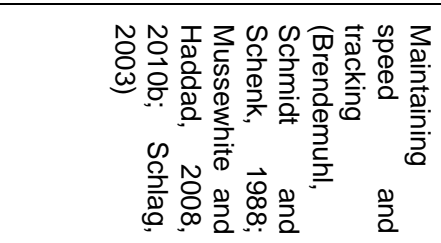 \\
\hline & $\times$ & $\times$ & & & $\times$ & $\times$ & 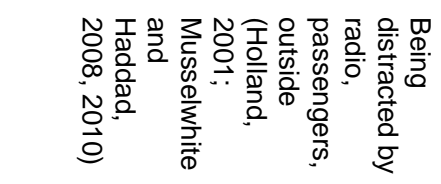 \\
\hline$\times$ & & & & & & & 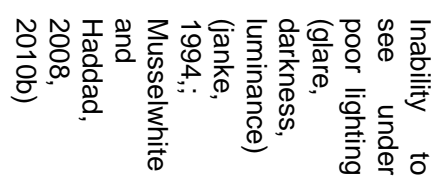 \\
\hline$\times$ & $x$ & $\times$ & & $x$ & & $\times$ & 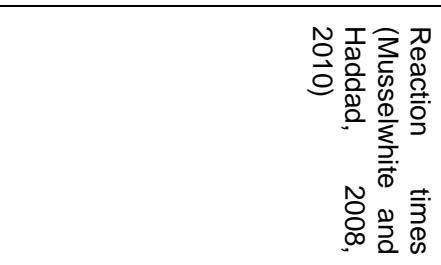 \\
\hline
\end{tabular}

Table 1: Mapping errors on the road in which older drivers are overrepresented to changes in cognition and eyesight in later life

(4) Perceptual speed. Difficulty in judging relative speeds of self and others often becomes more problematic with age (Maloula, et al., 2004)

(5) Working memory. Ageing is associated with reduced storage capacity and processing efficiency of the working memory (the memory used to perform immediate tasks). Hence, the ability to store new information and processing other information at the same time is diminished (Maloula et al.2004).

(6) Task switching. Ability to switch between different tasks, competently, efficiently and smoothly with minimal delay is diminished as people age (Maloula et al.2004)

(7) Eyesight. Between 15 and 65 years of age, not only does susceptibility to glare increase, the recovery time from glare increases from two to nine seconds' (Holland, 2001). Research suggests that by the age of 75 years old drivers may require 32 times the brightness than a 25 year old does in order to be able to see effectively.

These seven domains were then mapped to the errors older people make on the road identified in stage one. Once an agreement was reached among the expert advisory group, a matrix was created (see table 1). Failed to look properly could have been a result of all of the cognitive changes associated with ageing. Attention and eyesight affect the majority of different errors made on the road and hence are crucially important to driving in later life

\subsection{Stage three: Identifying computer based p[programmes which may help older drivers improve road user safety.}

This section examines a variety of cognitive computer-based training programmes that have been shown to be related to driver safety and that can be trained for. Such training is often referred to as brain training or brain fitness programmes. Brain training is "the engagement with a specific program 
Musselwhite, C.B.A. (in press) Assessment of computer-based training packages to improve the safety of older people's driver behaviour. Transport Planning \& Technology. To be published $2017 \mathrm{vol}$ 40 edition 1.

or activity that aims to enhance cognitive skill or general cognitive ability as a result of repetition over a circumscribed timeframe" (Rabipour and Raz, 2012, page 159). Brain training is related to the concept of neuroplasticity, that the brain is malleable can change or even grow in relation to stimuli (Calero and Navarro, 2007).

(1) The Useful Field of View (UFOV) Test and Training. Ball et al. (1988) define the Useful field of View (UFOV) as "the visual area in which information can be acquired within one eye fixation" (pg. 2210). They developed the concept based upon earlier work by Sanders (1970) who examined the concept under the name of "functional visual field". Sekuler \& Ball, (1986) developed an early version of a test of Useful Field of View that over time has turned into the computer based measure of cognitive processing speed and attention widely used today. The test consists of 3 sub-tests: (1) Processing Speed: Determines a person's ability for discriminating stimuli presented in central vision. Participants are required to identify and respond as quickly as possible to a silhouetted shape presented centrally; (2) Divided Attention: Builds on sub-test 1 by adding an additional target to be identified in the person's peripheral vision simultaneously and; (3) Selective Attention: Requires central and peripheral target identification (as in sub-tasks 1 and 2) but adds additional distractor shapes, in order to require the participant to have to switch between tasks.

Research has long suggested that poor results on UFOV relate to increased collision involvement and poorer driver performance (Ball and Owsley, 1992; Ball et al., 1991, 1993; Clay et al., 2005; Goode et al., 1998; Horswill et al., 2011; Mathias and Lucas, 2009; Staplin et al., 2003a,b). On specific driver ability tests there is still a relationship between poor UFOV performance and driver behaviour but the relationship tends to be quite weak (Selander et al., 2011) and in populations with mild cognitive impairments, the relationship is non-existent (Bohensky et al., 2007). Computer based training can improve results on UFOV which then translates to improving driver behaviour, for example, Ball et al. (2010) found ten 70 minute training sessions for older people led by an instructor over five weeks (two per week) reduced at-fault crashes by $51 \%$ over the following five years as compared to a control group. It can also contribute to faster reaction times and reduced risky driving manoeuvres (Roenker et al., 2003). Overall it has been shown to reduce premature driver cessation (Edwards et al., 2009a) and in turn improve physical health, quality of life and reduce depressive symptoms in older adults (Wollinsky et al., 2006a,b, 2009). It seems the training must be directly related to UFOV to be of impact, for example use of generic computer games, including Medal of Honour (1st person shooting game) and Tetris (shape arranging game), for example, although increase engagement and "flow" have few UFOV improvements and have no relation to improvements in driver behaviour (as measured on a simulator) (Belchior, 2007).

(2) Trail making test. The trail making test was introduced in 1938 (Partington \& Leiter, 1949) and used as part of the American Army induction test during the second world war and just after (AAITB, 1944). It has become part of the Halstead-Reitan Battery of tests (Reitan \& Wolfson, 1985) following its general use on studying brain damage and then non-damaged -and non-injured populations (e.g. Reitan, 1958). The Trail Making Test consists of two tests, Part A requires a participant to join up numbered shapes in sequential order from 1 to 25 as quickly as possible. This measures visual 
Musselwhite, C.B.A. (in press) Assessment of computer-based training packages to improve the safety of older people's driver behaviour. Transport Planning \& Technology. To be published $2017 \mathrm{vol}$ 40 edition 1.

search capability. Part B requires the participant to join numbers and letter together in order 1-A-2-B3-C and so on. Part B measures working memory and task switching ability.

Emerson et al (2012) found poorer scores on part A or part B were related to the number of crashes an older driver had. Staplin et al. (2003) found part B is related to at fault crashes in their sample of 2,500 drivers in three samples drawn from license renewal, medical referral, and residential community populations. Training can be improved via cognifit techniques (see Shatil et al., 2014).

(3) Motor-Free Visual Perception Test, Visual Closure sub-test. The Visual Closure subtest of the Motor-Free Visual Perception Test (MVPT/VC) measures a person's ability to visualise complete figures when only fragments are presented (Colarusso and Hammill, 1996). Naturally, this translates to driver behaviour, where drivers must recognise a sign, issue or problem that is partly hidden (e.g., pedestrian hidden by a parked car that may be about to move into the path of the driver). In a sample of 2500 drivers having their licence renewed at 70 years of age, The Motor-Free Visual Perception Test/Visual Closure subtest was found to be predictive of at-fault crash involvement (Staplin et al., 2003a,b).

(4) Delayed Recall Test. The Delayed Recall test, from the Mini-Mental Status Examination (Folstein, Folstein, and McHugh, 1975), is related to working memory. Working memory is important to safe driving because it allows a driver to recognise and remember signs, rules, navigation and moment to moment hazard detection and vehicle control (Staplin et al., 2003a,b). The test requires participants to recall three words after a delay (often 10 minutes in the first instance). Performance on the delayed recall test is related to at fault driver crashes (Staplin et al., 2003a,b). Delayed recall test can be improved with training, both specific memory training and more generic cognitive engagement with a task (see Kueider et al., 2012 for review), but whether such training is then related to reducing crashes at the wheel is yet to be tested.

(5) Computerized Maze Navigation. Participants trace a path through a computerised maze which progressively gets more complex. The test was originally designed by Professor Stanley Porteous as a non-verbal test of intelligence in 1914 (described in Porteous, 1950), and has been developed and refined over many years (see Lezak, 1995 for review). A study by Ott et al. $(2003,2008)$ found analysing participants $(n=133)$ completing a series of five mazes, calculating errors, planning time, drawing time and total time could distinguish older people's driving performance on a test track both for those with Alzheimer's disease and those with no cognitive impairment. The total test time was highly correlated with Trail Making A test and the Hopkins Verbal Learning Tests Trial 1 in both sets of participants. With a larger sample $(n=692)$ of older people aged $70-93$, Staplin et al $(2003 a, b)$ found maze test results are linked with collision involvement.

(6) Speed of processing training. Simple and choice reaction time was trained in a driver simulator with a group of older people with decreased cognitive function (Roenker, Cissell, Ball, Wadley, and Edwards, 2003). Simple reaction time was trained by making participants brake as fast as possible in relation to brake lights. Choice reaction time was trained by getting participants to react to different traffic signs which told the person to brake, turn the wheel or do nothing. The trained group had improved reaction time when compared to a control group who received no training, and improved on 
Musselwhite, C.B.A. (in press) Assessment of computer-based training packages to improve the safety of older people's driver behaviour. Transport Planning \& Technology. To be published $2017 \mathrm{vol}$ 40 edition 1.

an on-road evaluation of their driving especially on turning and signal use. These improvements were not noted at an 18 month follow-up, however.

(7) Dual n-back task for working memory. The n-task test was introduced by Kirchner (1958) and a variation of the test, the dual n-back, was first introduced by Jaeggi et al., (2003). In the ordinary nback task, the participant is presented with a series of stimuli, for example words or letters, and must indicate when the current stimulus matches one from $n$ steps earlier in the sequence. The $n$ is changed and made more difficult if the participant is performing well, so the task is incremental. In the dual-task version, two independent sequences are presented at the same time, often one is presented verbally and one will be presented visually. Seidler et al., (2010) gave participants training for the test 5 days a week (lasting around 20-25 minutes a day) for five weeks, totalling 25 sessions, while a control received training on trivia. Those who received training improved other elements of working memory and this did transfer to driving performance, albeit measured on a driver simulator.

\section{Discussion}

Performance by older people on the Useful Field of View (UFOV), Trail Making Test part A and B (TMT/A, TMT/B), Motor-Free Visual Perception Test, Visual Closure Subtest (MVP T/VC), Delayed Recall, Maze test and Dual $\mathrm{N}$ task have all been shown to be related to number of collisions they have. Of these only UFOV and Maze test are related to driver behaviour in general, not just collisions per se. Speed of processing has also been found to be related to driver performance only, but not to number of collisions. Training has been shown to improve performance on the UFOV, TMT $A / B$, Delayed Recall, Speed of Processing and the Dual $\mathrm{N}$ test. Although it might be assumed improved performance on the test following training would transfer to improved driver behaviour or reduce driver collisions in those tests, research has not always been carried out that demonstrates this. Hence, we can only surmise that it is highly likely such training will have an effect on driver performance. There are only two tests where research demonstrates transference of training improvements to better driving, UFOV and Dual $\mathrm{N}$ fitness tests. UFOV has had the most attention in this area, having been shown to correlate to many different domains of driver behaviour in older adults including crash involvement, driver performance, driver cessation and associated mental health and wellbeing domains. But it must be noted that it has had most research carried out in this area; other tests may still improve driver behaviour in similar ways but as yet have not been tested and more research is certainly required.

Mapping the training to known older driver issues, from stage two of the research to these tests, shows that the UFOV again covers many particular problems, for example those involving attention, cognitive overload, cognitive processing speed and perceptual speed (see table 2). In combination with TMT A and B which covers working memory, task switching and visual search, the main cognitive issues related to older drivers are covered. These tests have been shown to be related to driver collisions and/or driver behaviour and can be trained for. Although more work is needed on how best to combine such training and how to present such training in a driver context, it is suggested these 
Musselwhite, C.B.A. (in press) Assessment of computer-based training packages to improve the safety of older people's driver behaviour. Transport Planning \& Technology. To be published $2017 \mathrm{vol}$ 40 edition 1.

are the most appropriate tests and training to be considering when wanting to improve driver training for older people.

\begin{tabular}{|l|l|l|l|l|l|l|l|l|}
\hline & UFOV & $\begin{array}{l}\text { TMT } \\
\text { A }\end{array}$ & $\begin{array}{l}\text { TMT } \\
\text { B }\end{array}$ & $\begin{array}{l}\text { MVPT } \\
\text { VC }\end{array}$ & $\begin{array}{l}\text { Delayed } \\
\text { Recall }\end{array}$ & Maze & $\begin{array}{l}\text { Speed } \\
\text { processing }\end{array}$ & $\begin{array}{l}\text { Dual } \\
\text { Attention }\end{array}$ \\
\hline $\begin{array}{l}\text { Cognitive } \\
\text { Overload }\end{array}$ & $\mathrm{x}$ & & & & & $\mathrm{x}$ & & \\
\hline $\begin{array}{l}\text { Cognitive } \\
\text { processing speed }\end{array}$ & $\mathrm{x}$ & & & & & & $\mathrm{x}$ & $\mathrm{x}$ \\
\hline Perceptual speed & $\mathrm{x}$ & & & & & & & \\
\hline Working memory & & & $\mathrm{x}$ & $\mathrm{x}$ & $\mathrm{x}$ & & & \\
\hline Task switching & & & $\mathrm{x}$ & & & $\mathrm{x}$ & & \\
\hline Visual search & & $\mathrm{x}$ & & $\mathrm{x}$ & & $\mathrm{x}$ & & \\
\hline Eyesight & $\mathrm{x}$ & & & $\mathrm{x}$ & & $\mathrm{x}$ & & \\
\hline Related to crashes & $\mathrm{x}$ & $\mathrm{x}$ & $\mathrm{x}$ & $\mathrm{x}$ & $\mathrm{x}$ & $\mathrm{x}$ & & $\mathrm{x}$ \\
\hline Related to driver \\
behaviour
\end{tabular}

Table 2: Overview of cognitive computer packages and the relationship of these to cognitive and physiological changes in older people associated with collisions, whether they can be trained for and whether research has found them to be related to crashes or driver improvement

Education and driver training programmes targeted directly at improving driver behaviour sometimes involve some of the cognitive tests mentioned above coupled with scenario discussions and on-road evaluations and training. Suites of cognitive (and physical) tests are found in Cognifit, CogMed and DriveFit, for example, as well as appearing within the education and training programmes. Overall, these programmes are evaluated well, older people enjoy the training and having a chance to learn something new and they enjoy the opportunity to reflect on their skills and abilities and focus in on the limitations. Yet, bringing together the most appropriate tests in the best manner has not been fully researched, especially in relation to driving based outcomes. Some studies suggest driver behaviour can improve but links to fewer collisions has not yet been studied. The only study to include this as a measure has found an increase in collisions, perhaps being linked to creating over confidence in the 
Musselwhite, C.B.A. (in press) Assessment of computer-based training packages to improve the safety of older people's driver behaviour. Transport Planning \& Technology. To be published $2017 \mathrm{vol}$ 40 edition 1.

older driver (Nasvadi and Vavrik, 2007). Improvements in driver behaviour where noted also tend to be fairly short-lived.

Packaging this training as an attractive and coherent programme is more problematic. People who engage in training are often at either end of the spectrum, they are motivated, conscientious people who want to improve their driving, often those who are already very self-aware, very careful and overall very good drivers, or they are those who have been referred to training due to an identified problem, either health or an issue on the road (they been involved in a collision or been spotted driving dangerously or poorly by the police, for example). There will inevitably be a large gap of people in the middle of these extremes who would clearly benefit from training. Some of these will believe they are already good enough, some will believe that training is of little help, some will be anxious about being told to give-up should they attend training, some maybe anxious about being evaluated, especially in front of others. How to motivate this group to interact with training has not yet been investigated. Self-completion training can help those who do not want to be assessed and evaluated in a public setting ( see Lang et al (2013) for a good review). These have been evaluated to be shown to help older people become more self-aware of their own driving imitations and help them formulate intentions to change. There is evidence from the SAFER driving tool, for example, that completion of the self-awareness programme can improve driver performance (Molnar et al., 2010) but there is no evidence it reduces collisions or how long improvements lock in. Additionally, Dunn and Hellier (2011) note that actually there is little engagement from older drivers with such tools beyond an initial selection. Hence, any self-completion training programme needs a mechanism to keep people engaged for a longer time period. Indeed this is an issue across all training interventions. Training is often a one-off event, perhaps a system involving continuous feedback and monitoring would be more appropriate and more synonymous with everyday driving. At least training could be provided at regular intervals to maintain standards. Research to date has not really addressed the right levels of interval of presenting an intervention in order to make the appropriate improvements to driver behaviour or reduce crashes.

One way of making the training attractive is to package the training in the form of a game. There are a growing number of older digital gamers (Musselwhite, et al., 2016) and there could be a market for a game that expands cognition in relation to driving. Research to date suggests that cognitive abilities can be changed by playing video games, both purpose built games and also off the shelf games (e.g. Basak, et al., 2008; Belchior et al. 2012)., Green and Bavelier $(2006,2003)$ stress how first-person shooter games, for example, can improve UFOV and other cognitive skills. Anguera et al (2013) have found cognitive control improves through playing of games. However, translation of improvement to driver performance has yet to be found (Belchior. 2007).

Elements that have not been looked at in conjunction with training and interventions for older people include psychosocial responses to driving, including emotive reactions, attitudes and perceptions. Given the emotive nature of giving-up driving, this seems somewhat of an omission. Attitudes have 
Musselwhite, C.B.A. (in press) Assessment of computer-based training packages to improve the safety of older people's driver behaviour. Transport Planning \& Technology. To be published $2017 \mathrm{vol}$ 40 edition 1.

been recognised as an important component of driver training for novice drivers (see Musselwhite, 2010) but have largely been disregarded for older drivers.

Ultimately, there is always the need for careful evaluation of a proposed intervention. Most worryingly with this type of training is the potential for over confidence that may lead to more risky behaviour and consequently more crashes. Alternatively the opposite may happen, people may lose confidence unnecessarily. The need for balancing this with appropriate feedback based on robust evaluation is crucial.

Overall any future plans for training should make sure that the package works within norms and expectations and have real-time quality feedback. Training that has reported to be successful is usually interactive (see also Henderson, 2003; Molnar et al., 2003) and often involves some form of social element. For example, in training and education sessions, discussions with others have been useful in getting individuals to reflect on their behaviour (Musselwhite, 2010). Behaviour change can also be enhanced through social comparison and facilitation, so comparing progress on training interventions with those identified as similar to themselves can help with maximising the success of the intervention (Musselwhite, 2010). This need not be in person but could be virtual connections if the training was done remotely on computers, for example. A suite of training programmes should be available and tailored to the older person's needs.

The suite should include cognitive tests of UFOV along with TMT A and B as well as encouraging neck and shoulder exercises and possibly general fitness. It should be investigated how far these might be developed as interactive games and within a driving format. Could UFOV and TMT A and B, for example, be converted into a game with incremental changes and levels to complete? Could UFOV or TMT A and B, for example, be developed as a hazard perception test or use scenes from a roadway?

Recommendations for future training programmes for older people to improve driver behaviour should include the UFOV and the TMT A and B test. A screening procedure linked to incremental training programmes with feedback akin to a game style package is suggested. However, it must be noticed there is little consensus in current research and it cannot be emphasised enough that more research is needed to identify if the benefits to actual driver behaviour are sustained. 
Musselwhite, C.B.A. (in press) Assessment of computer-based training packages to improve the safety of older people's driver behaviour. Transport Planning \& Technology. To be published $2017 \mathrm{vol}$ 40 edition 1.

\section{References}

AITB. (1944). Army Individual Test Battery. Manual of directions and scoring. Washington, DC: War Department, Adjutant General's Office.

Anguera, J.A., Boccanfuso, J., Rintoul, J.L., Al-Hashimi, O., Faraji, F., Janowich, J., Kong E., Laraburro, Y., Rolle, C., Johnston, E., \& Gazzaley, A. (2013) Video game training enhances cognitive control in older adults. Nature. 501: 97-101.

Ball, K., Owsley, C., Sloane, M.E.., Roenker, D.L., and Bruni, J.R. (1993) Visual attention problems as a predictor of vehicle crashes in older drivers. Invesigative Ophtalmology and Visual Science, 34(11): 3110-23

Ball, K., Edwards, J. D., Ross, L. A., and McGwin, G. (2010). Cognitive Training Decreases Motor Vehicle Collision Involvement Among Older Drivers.Journal of the American Geriatrics Society, 58(11), 2107-2113.

Ball, K. and Owsley,C. (1991). Identifying correlates of accident involvement for the older driver. Hum Factors, 33(5): p. 583-95.;

Ball, K.. Owsley, C and Sloane M. (1991), Visual and cognitive predictors of driving problems in older adults. Exp Aging Res, 17(2): p. 79-80.;

Ball, K.K., Beard, B.L. Roenker, D.L. Miller, R.L. and Griggs D.S. (1988) Age and visual search: Expanding the useful field of view Journal of the Optical Society of America. A. Optics, Image Science, and Vision, 5 (12) 2210-2219

Basak, C., Boot, W. R., Voss, M. W., \& Kramer, A. F., (2008). Can Training in a Real-Time Strategy Video Game Attenuate Cognitive Decline in Older Adults? Psychology and Aging, 23(4):765-777.

Belchior, P. (2007). Cognitive training with video games to improve driving skills and driving safety among older adults. Dissertation Abstracts International, 68(9-B), 5897.

Belchior, P., Marsiske, M., Sisco, S. M., Yam, A., Bavelier, D., Ball, K., \& Mann, W. C. (2012). Video game training to improve selective visual attention in older adults. Computers in Human Behavior, 29:1318-1324.

Bohensky, M., Charlton, J., Odell, M and Keeffe, J. (2007). Implications of Vision Testing for Older Driver Licensing. Traffic Injury Prevention, 9 (4), 304-313

Brendemuhl, D., Schmidt, U., and Schenk, N. (1988). Driving Behaviour of Elderly Motorists in Standardized Test Runs under Road Traffic Conditions" In J.A. Rothengatter and R.A. de Bruin (Eds.), Road User Behaviour: Theory and Research (pp. 310-318). Wolfeboror, NH: Van Gorcum

Calero MD and Navarro E. (2007) Cognitive plasticity as a modulating variable on the effects of memory training in elderly persons. Archives of Clinical Neuropsychology.22:63-72.

Clarke, D. D., Ward, P., Truman, W., and Bartle, C. (2009) Collisions involving older drivers: An indepth study. London, Department for Transport 
Musselwhite, C.B.A. (in press) Assessment of computer-based training packages to improve the safety of older people's driver behaviour. Transport Planning \& Technology. To be published $2017 \mathrm{vol}$ 40 edition 1.

Clay O.J., Wadley V.G., Edwards J.D., Roth D.L., Roenker D.L., and Ball K. (2005). Cumulative metaanalysis of the relationship between Useful Field of View and driving performance in older adults: Current and future implications. Optometry and Vision Science. ;82:724-73

Colarusso, R. and Hammill, D. (1996). Motor free visual perceptual test, examiner's manual, Novato, CA: Academic Therapy Publications, Inc.

Der, G., and Deary I. J. (2006) Age and sex differences in reaction time in adulthood: Results from the UK Health and Lifestyle Survey. Psychology and Aging, 21, 62-73

DfT (Department for Transport) (2015). Reported road casualties Great Britain: annual report 2014. Department for Transport: London, UK

DfT (Department for Transport) (2012) Linking Police and Hospital data on Road Accidents in England: 1999 to 2009 results, Department for Transport: London, UK.

Dunn, V. and Hellier, E. (2011) A review of the evidence relating to cognitive training for older drivers, Devon County Council and Knowledge Transfer Project with Plymouth University

Edwards, J.D., P.B. Delahunt, and H.W. Mahncke (2009a), Cognitive Speed of Processing Training Delays Driving Cessation. Gerontology Series A: Biological Sciences and Medical Sciences, ,64(12), 1262-7

Edwards, J. D., Perkins, M., Ross, L. A., and Reynolds, S. L. (2009b). Driving status and three-year mortality among community-dwelling older adults. Journal of Gerontology Series A: Biological Sciences and Medical Sciences, 64 , 300-305.

Emerson J, Johnson A, Dawson J, Uc E, Anderson S, and Rizzo M. (2012) Predictors of driving outcomes in advancing age.. Psychology and aging. 27(3):550-9.

Folstein, M., Folstein, S.E., and McHugh, P.R. (1975). "Mini-Mental State" a Practical Method for Grading the Cognitive State of Patients for the Clinician. Journal of Psychiatric Research, 12(3); 189198. Fonda, S.J., Wallace, R.B. and Herzog, A.R. (2001). Changes in Driving Patterns and Worsening Depressive Symptoms Among Older Adults. The Journal of Gerontology, Series B: Psychological Sciences and Social Sciences 56(6), S343-S351.

Goode, K.T., Ball, K.K., Sloane, M.E., Roenker, D.L., Roth, D.L., Myers, R.S., and Owsley, C. (1998). Useful field of view and other neurocognitive indicators of crash risk in older adults. Journal of Clinical Psychology in Medical Settings, 5, 425-440.

Green, C. S., and Bevalier, D. (2003). Action video game modified visual selective attention. Nature, 429:534-37.

Green CS, and Bavelier D. (2006) The cognitive neuroscience of video games. In: Humphreys L, Messaris P, editors. Digital media: Transformations in human communication. New York: Peter Lang; pp. 211-223.

Henderson, M. (2003). Education, Training and Publicity in Road Safety. Monash University: Accident Research Centre. Report No. 22 
Musselwhite, C.B.A. (in press) Assessment of computer-based training packages to improve the safety of older people's driver behaviour. Transport Planning \& Technology. To be published $2017 \mathrm{vol}$ 40 edition 1.

Holland, C. (2001). Older Drivers: a Review, London: Department for Transport

Horswill, M.S., Anstey, K.J., Hatherly, C.G. and Wood, J.M. (2010). The crash involvement of older drivers is associated with their hazard perception latencies. $J$ Int Neuropsychol Soc; 16(5): 939-44

Jaeggi, S. M., Seewer, R., Nirkko, A. C., Eckstein, D., Schroth, G., Groner, R., et al., (2003). Does excessive memory load attenuate activation in the prefrontal cortex? Load-dependent processing in single and dual tasks: functional magnetic resonance imaging study, Neuroimage 19(2) 210-22

Janke, M. (1994). Age-related disabilities that may impair driving and their assessment: Literature review. Department of Motor Vehicles, Sacramento, United States

Jevas, S. and Yan, J.H. (2001). The effect of aging on cognitive function: A preliminary quantitative analysis. Research Quarterly for Exercise and Sport: Abstracts of Completed Research, 72(1), A-49

Kirchner, W. K. (1958), Age differences in short-term retention of rapidly changing information. Journal of Experimental Psychology, 55(4), 352-358.

Lang, B., Parkes, A. \& Fernández-Medina, K. (2013). Driving choices for the Older Motorist. The role of self-assessment tools. London: RAC Foundation

Langford J., Methorst, R. and Hakamies-Blomqvist, L. (2006) Older drivers do not have a high crash risk-A replication of low mileage bias, Accident Analysis and Prevention, 38 (3) , 574-578.

Lezak, M.D. (1995) Neuropsychological Assessment, , Oxford University Press,: Oxford :UK

Ling, D.J. and Mannion, R. (1995). Enhanced Mobility and Quality of Life of Older People: Assessment of Economic and Social Benefits of Dial-a- Ride Services. In Proceedings of the Seventh International Conference on Transport and Mobility for Older and Disabled People, Vol. 1, DETR, United Kingdom

Marottoli, R. A. (2000). Consequences of driving cessation: Decreased out-of-home activity levels. Journal of Gerontology: Social Sciences, 55, S334-S340.

Marottoli, R. A., C. F. Mendes de Leon, T. A. Glass, and C. S. Williams. 1997. Driving Cessation and Increased Depressive Symptoms: Prospective Evidence From the New Haven EPESE. Journal of the American Geriatrics Society 45 202-206.

Mathias, J. L. and Lucas, L. K. (2009). Cognitive predictors of unsafe driving in older drivers: a metaanalysis. International Psychogeriatrics, 21(4): 637-653.

Mitchell, C.G.B. (2013) The licensing and safety of older drivers in Britain. Accident Analysis and Prevention, 50, 732-741.

Molnar, L.J., Eby, D.W., Kartje, P.S. and St. Louis, R. (2010). Increasing self awareness among older drivers: The role of self-screening. Journal of Safety Research, 41, 367-373.

Molnar, L., Eby, D. and Miller, L. (2003). Promising Approach for Enhancing Elderly Mobility UMTRI 2003-14. 
Musselwhite, C.B.A. (in press) Assessment of computer-based training packages to improve the safety of older people's driver behaviour. Transport Planning \& Technology. To be published $2017 \mathrm{vol}$ 40 edition 1.

Musselwhite, C. B. A. (2010). The Role of Education and Training in Helping Older People to Travel after the Cessation of Driving. International Journal of Education and Ageing, 1(2), 197-212.

Musselwhite, C.B.A. (2011). Successfully giving up driving for older people. Discussion Paper. International Longevity Centre - UK.

Musselwhite, C.B.A. and Haddad, H. (2008). A Grounded Theory exploration into the driving and travel needs of older people. Proc. 40th Universities Transport Study Group Conference, University of Southampton, Portsmouth, January

Musselwhite, C.B.A. and Haddad, H. (2010a). Mobility, accessibility and quality of later life. Quality in Ageing and Older Adults, 11(1), 25-37.

Musselwhite, C.B.A. and Haddad, H. (2010b). Exploring older drivers' perception of driving. European Journal of Ageing, 7(3), 181-188.

Musselwhite, C., Marston, H.R. and Freeman, S. (2016) From Needy and Dependent to Independent Homo Ludens: Exploring Digital Gaming and Older People Games and Culture. 11(1-2) 3-6

Musselwhite, C.B.A. and Shergold, I. (2013). Examining the process of driving cessation in later life. European Journal of Ageing. 10(2), 89-100

Nasvadi, G.E. and Vavrik, J. (2007). Crash risk of older drivers after attending a mature driver education program. Accident Analysis and Prevention, 39, 1073-1079.

Office of National Statistics (ONS) (2013). Population statistics and estimates by area. Titchfield, Fareham: Office of National Statistics

Ormerod, M. Newton, R., Philips, J., Musselwhite, C., McGee, S and Russell, R. (2015). How can transport provision and associated built environment infrastructure be enhanced and developed to support the mobility needs of individuals as they age? Future of an ageing population: evidence review Foresight, Government Office for Science, London, UK.

Ott, B.R., Festa E.K., Amick M.M., Grace, J. Davis, J.D. and Heindel W.C. (2008). Computerized maze navigation and on-road performance by drivers with dementia Journal of Geriatric Psychiatry and Neurology, 21 (1), 18-25

Ott, B.R. Heindel, W.C. Whelihan, W.M. Caron, M.D. Piatt, A.L. and DiCarlo M.A. (2003) Mazes test performance and reported driving ability in early dementia Journal of Geriatric Psychiatry and Neurology, 16, 151-155

Oxley, J., Fildes, B., Corben, B. and Langford, J. (2006) Intersection design for older drivers. Transportation Research Part F: Traffic Psychology and Behaviour, 9(5), 335-346.

Parkington JE, and Leiter RG. (1949) Partington's Pathway Test. The Psychological Service Center Bulletin.;1:9-20.

Porteus, S. (1950), The Porteus maze test and intelligence, Pacific Books, Palo Alto, CA., OCLC: 
Musselwhite, C.B.A. (in press) Assessment of computer-based training packages to improve the safety of older people's driver behaviour. Transport Planning \& Technology. To be published $2017 \mathrm{vol}$ 40 edition 1.

Preusser, D., Williams, A., Ferguson, S., Ulmer, R. and Weinstein, H. (1998). Fatal crash risk for older drivers at intersections. Accident Analysis and Prevention, 30(2): 151-159.

Rabipour, S and Raz, A. (2012) Training the brain: Fact and fad in cognitive and behavioural remediation Brain and Cognition, 79 159-179

Ragland, D. R., W. A. Satariano, and K. E. MacLeod. (2005). Driving Cessation and Increased Depressive Symptoms. The Journals of Gerontology Series A: Biological Sciences and Medical Sciences 60 399-403.

Reitan RM. (1958). Validity of the Trail Making test as an indicator of organic brain damage. Perception and Motor Skills.;8:271-276.

Reitan, R. M., and Wolfson, D. (1985). The Halstead-Reitan Neuropsycholgical Test Battery: Therapy and clinical interpretation. Tucson, AZ: Neuropsychological Press

Roenker DL, Cissell GM, Ball KK, Wadley VG, and Edwards JD. (2003) Speed-of-processing and driving simulator training result in improved driving performance. Human Factors.,45: 218-233

Sanders A.F. (1970) Some aspects of the selective process in the functional visual field Ergonomics, 13 (1) pp. 101-117

Schlag, B. (2003). Safety and Accidents of Older Drivers: The German Perspective. In: K. W. Schaie, H.-W. Wahl, H. Mollenkopf, \& F. Oswald (eds.): Ageing in the Community: Living Arrangements and Mobility. Springer.

Seidler, R. D., Bernard, J. A., Burutolu, T. B., Fling, B. W., Gordon, M. T., Gwin, J. T., Kwak, Y., and Lipps, D. B. (2010). Motor control and aging: links to age related brain structural, functional, and biochemical effects. Neurosci. Biobehav. Rev. 34, 721-733

Sekuler, R. and Ball K. (1986), Visual localization: Age and practice Journal of the Optical Society of America. A. Optics, Image Science, and Vision, 3 (6) pp. 864-867

Selander H., Lee H. C., Johansson K., and Falkmer T. (2011). Older drivers: on-road and off-road test results. Accid. Anal. Prev. 43, 1348-1354

Shatil E, Mikulecka J, Bellotti F, and Bures V (2014) Novel television-based cognitive training improves working memory and executive function. PLOS ONE9: e101472 Available at http://www.ncbi.nlm.nih.gov/pubmed/25405755 (last accessed 30/11/15)

Staplin, L., Lococo, K. H., Gish, K. W. and Decina, L.E. (2003a). Model Driver Screening and Evaluation Program. Volume 2: Maryland Pilot Older Driver Study. Washington, D.C.: National Highway and Traffic Safety Administration. Available at: http://www.nhtsa.dot.gov/people/injury/olddrive/modeldriver/ (last accessed 30/11/15)

Staplin, L., Lococo, K. H., Gish, K. W., and Decina, L.E. (2003b). Model Driver Screening and Evaluation Program: Guidelines foe Motor Vehicle Administrators. . Washington, D.C.: National Highway and Traffic Safety Administration. Available at: http://www.nhtsa.dot.gov/people/injury/olddrive/modeldriver/ (last accessed 30/11/15) 
Musselwhite, C.B.A. (in press) Assessment of computer-based training packages to improve the safety of older people's driver behaviour. Transport Planning \& Technology. To be published $2017 \mathrm{vol}$ 40 edition 1.

UN (United Nations) (2013). World Population Ageing 2013. United Nations: New York. http://www.un.org/en/development/desa/population/publications/pdf/ageing/WorldPopulationAgeing20 13.pdf (last accessed 30/11/15)

Van Elsland, P., and Dominique, F. (2000). Elderly Drivers: What Errors do they Commit on the Road. Human Factors and Ergonomics Society Annual Meeting Proceedings 44(20): 259-259.

Welford, A. T. (1977). Motor performance. In J. E. Birren and K. W. Schaie (Eds.), Handbook of the Psychology of Aging. New York: Van Nostrand Reinhold, , 450-496.

Windsor, T. D., K. J. Anstey, P. Butterworth, M. A. Luszcz, and G. R. Andrews. (2007). The Role of Perceived Control in Explaining Depressive Symptoms Associated with Driving Cessation in a Longitudinal Study. The Gerontologist 47 215-223.

WRVS. (2013). Going Nowhere Fast.Impact of inaccessible public transport on wellbeing and social connectedness of older people in Great Britain. Available at http://www.royalvoluntaryservice.org.uk/Uploads/Documents/Reports\%20and\%20Reviews/Trans\%20r eport GB web v1.pdf (last accessed 30/11/15)

Zanto T. P. and Gazzaley A. (2014). Attention and ageing. In Nobre A. C. Kastner S. (Eds.) The Oxford handbook of attention Oxford, UK: Oxford University. 927-971. 